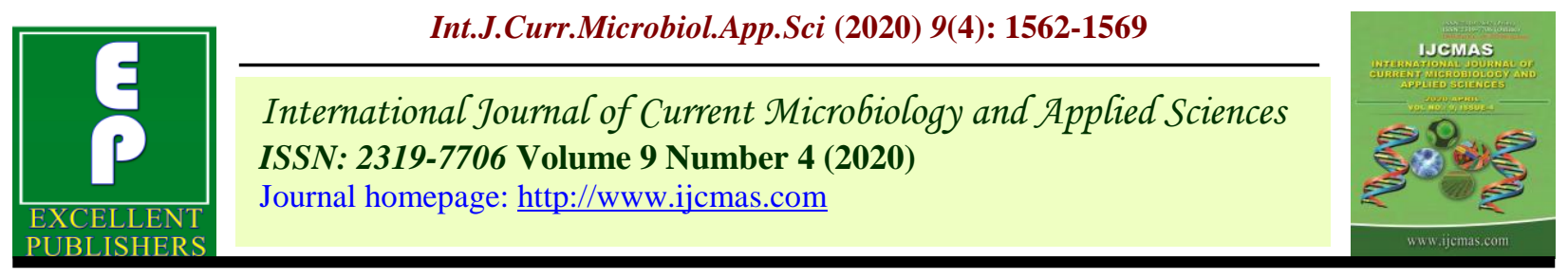

Original Research Article

https://doi.org/10.20546/ijcmas.2020.904.183

\title{
Microsatellite based Genetic Characterization Study in Native Chicken Population of North Gujarat, India
}

\author{
D. F. Chaudhary*, R. S. Joshi, D. N. Rank and J. D. Chaudhary \\ Department of Animal Genetics \& Breeding, College of Veterinary Science and Animal \\ Husbandry, Anand Agricultural University, Anand-388001
}

\section{A B S T R A C T}

\begin{tabular}{|l|}
\hline Keyw or d s \\
Native chicken \\
population of \\
$\begin{array}{l}\text { Gujarat, } \\
\text { Microsatellite, } \\
\text { Genetic } \\
\text { characterization }\end{array}$ \\
\hline Article Info \\
\hline $\begin{array}{l}\text { Accepted: } \\
12 \text { March 2020 } \\
\text { Available Online: } \\
10 \text { April 2020 }\end{array}$ \\
\hline
\end{tabular}

The present study was undertaken for genetic characterization of native chicken population of North Gujarat by using 25 microsatellite markers done into seven multiplexed set. A total of 240 alleles were found where observed number of alleles per locus varied from 6 (ADL 172, MCW 43) to 15 (ADL 136). The mean observed numbers of alleles were found to be 9.60. The overall means for observed and expected heterozygosities were 0.531 and 0.771 respectively, with the ranges of 0.067 (ADL 172) to 0.800 (ADL 23) and 0.518 (ADL 158) to 0.892 (ADL 136), respectively. The Fixation index $\left(\mathrm{F}_{\mathrm{IS}}\right)$ value for all 25 microsatellite loci ranged from 0.075 (MCW 59) to 0.683 (MCW 73) with mean of 0.309 . Polymorphic Information Content (PIC) value was ranging from 0.494 (ADL 158) to 0.883 (ADL 136) with a mean of 0.747 . The high number of observed alleles and high heterozygosity indicated presence of high genetic variability in native chicken and selected microsatellites were highly polymorphic and proved very useful for breed characterization.

\section{Introduction}

The Native chicken population represents an important source of genetic resources for future commercial or non-commercial purposes. They more adapted to the local environment; have a natural resistance to some serious endemic diseases and could be selected under stressful environments (Kolstad and Abdou, 2000). Genetic Characterization of the native chicken population is necessary to identify them and for the effective conservation of their valuable gene pool against future needs (Soltan et al., 2016). In Banaskantha, Sabarkantha, Arvalli and Mahisagar districts of North Gujarat, India, Native chicken population is being reared by tribal communities for a source of income as backyard poultry farming.

They are having different or unique characters from the known breeds of Gujarat and adjoining state. Although there is an importance of native chicken in tribal/rural area but genetic background exists among population is yet not known. Somehow, 
Mechanization, unplanned and indiscriminate breeding among native stocks and human bias in favour of certain breeds are directly or indirectly responsible for the dilution of Indian livestock germplasm.

Hence, characterization of indigenous germplasm is essential for their conservation. Different genetic marker systems have successfully been used for estimation of genetic diversity in poultry. Microsatellite markers being the choice of genetic diversity due to high variability, high mutation rate, large number distribution throughout the genome and co-dominant inheritance.

Despite the value of native chicken population in tribal areas, information pertaining to their genetic makeup (genetic variability, environment adaptability and disease resistance) is lacking. In this context, current study was undertaken on Microsatellite based Genetic Characterization of Native Chicken Population of North Gujarat.

\section{Materials and Methods}

Sixty blood samples were collected randomly from non-related chickens from three pockets (Talukas) viz., Amirgadh, Vadgam and Danta of Banaskantha district of North Gujarat. The DNA was isolated using standard laboratory protocol (John et al., 1991). The 25 microsatellite primers were selected based on their fragment size and fluorescent dye label (Table 1).

PCR amplification of 25 microsatellite loci was done into seven multiplexed set. The genotyping was performed using ABI PRISM 3500 Genetic Analyser, automated DNA Sequencer and Gene Mapper software version 4.1 (Applied Biosystem, USA). The statistical analysis was performed using Gene Alex version 6.503 and Cervus version 3.0.7.

\section{Results and Discussion}

\section{Observed and effective number of alleles}

Among 25 microsatellite loci tested, all were found to be polymorphic. A total of 240 alleles were observed where the number of alleles per locus among the polymorphic markers ranged from 6 (ADL 172, MCW 43) to 15 (ADL 136) in native chicken indicating considerable variation in the distribution of allele frequencies between loci observed in population. The number of effective allelic (Ne) frequencies of each microsatellite loci ranged from 2.074 (ADL 158) to 9.219 (ADL 136). The mean number of observed allele 9.60 was quite high as compared to the mean number of effective alleles 4.932. However, most of the alleles were in low frequency and is reflected by a dramatic decrease in the effective number of alleles in native chicken population.

Mean number of effective alleles found to be less as compared observed alleles supported by Pandey et al., (2003) in which three chicken breeds Aseel, Miri and Nicobari were genotyped where the number of alleles in Aseel breed varied from 3(MCW 7, ADL 102, ADL 267) to 9 (ADL 136) with average of 4.80. Effective numbers of alleles were less than the observed values averaging as 3.09. The number of alleles in Miri breed ranged from 3 (MCW 7) to 8 (ADL 136, ADL 210) with average of 5.27. Effective numbers of alleles in Miri were less than the observed number of alleles with average of 3.39. Nicobari breed revealed average number of alleles as 4.27 with the range from 2 (MCW 14, MCW7, MCW 41, ADL 171) to 7 (ADL 176, ADL 136). In Nicobari the effective numbers of alleles are less than the observed number of alleles with average of 3.15 .

Similar results found in Pandey et al., (2005) where 161 different alleles observed in 
Ankleshwar chicken using 25 microsatellite markers in which the number of allele per locus ranged from 4 (ADL 20, MCW 7, MCW 59 and ADL 40) to 11 (ADL 171). The number of effective allelic frequencies of each microsatellite loci ranged from 1.437 (MCW 4) to 6.387 (HUJ 12). The mean number of observed allele 6.44 was quite high as compared to the mean number of effective alleles 2.910 .

Comparable results found in Vij et al., (2006) where a total of 218 alleles observed in 26 microsatellite loci in Punjab Brown chicken. The number of alleles per locus varied from 4 (LEI 90, MCW 84 and LEI 174) to 14 (LEI 120 and LEI 82). Also, the mean number of observed allele (mean $\mathrm{Na}=8.38$ ) was quite high as compared to the mean number of effective alleles $(\mathrm{Ne}=4.427)$. Tantia et al., (2006) also reported the minimum number of alleles 8 (MCW 328 and MCW 84) and maximum number of alleles 25 (LEI 147) in 15 indigenous chicken breeds of India. The mean number of alleles was 15.88. They opined that the indigenous poultry was highly variable at microsatellite loci.

High variability was present in indigenous chicken also supported by Mukesh et al., (2011) where 173 alleles with mean of 11.53 observed in which 32 (LEI 234) yielded the highest number of alleles while5 (LEI 166, MCW 222 and MCW 98) yielded the lowest number of alleles in Red Jungle fowl in Northern India.Variation in observed and effective alleles also found in Soltan et al., (2017) where observed number of 182 alleles in Sinai and Norfa chicken from Egypt. The overall mean number of alleles per locus across all investigated populations was 9.1 alleles. The lowest total number of alleles was observed for MCW 284 (5 alleles), while LEI 234 showed the highest total number of alleles (15 alleles).

\section{Heterozygosity of microsatellite loci}

Heterozygosity is an appropriate measure of genetic variability within a population. In present study observed heterozygosity values ranged from 0.067 (ADL 172) to 0.800 (ADL 23) whereas the range of expected heterozygosity was 0.518 (ADL 158) to 0.892 (ADL 136). The average - observed heterozygosity and expected heterozygosity value were found to be 0.531 and 0.771 , respectively (Table 2). Thus, high genetic variation is observed in native chicken population. Similar to that Pandey et al., (2003) observed an average heterozygosity values were to be $0.59,0.61$ and 0.57 respectively in Aseel, Miri and Nicobari breeds of India and overall heterozygosity value for all the microsatellite loci among all the three varieties was observed to be 0.59.Pandey et al., (2005) reported the observed heterozygosity values ranging from 0.216 (ADL 171) to 0.850 (ADL 20) in Ankleshwar chicken whereas the range of expected heterozygosity was 0.308 (MCW 4) to 0.854 (HUJ 12). The average - observed heterozygosity value was found to be 0.527 . Rajkumar et al., (2008) also reported the mean observed heterozygosity levels among the populations ranging from 0.55 in Dahlem Red to 0.73 in Desi (non-descript) chicken.

The overall mean observed and expected heterozygosity estimates were 0.64 and 0.68 in 8 chicken breeds similar to present study. Mukesh et al., (2011) also reported mean observed heterozygosity to be 0.391 which was lower than the expected heterozygocity (0.755) in Red Jungle fowl of Northern India similar to present estimate. Soltan et al., (2017) reported the mean observed heterozygosity (Ho) to be 0.502 and ranged across loci from 0.00 to 0.964 , whereas the mean expected heterozygosity $(\mathrm{He})$ was 0.814 ranged between 0.518 to 0.912 in Sinai and Norfa chicken from Egypt. 
The average observed and expected heterozygote frequencies within populations across loci were 0.502 (ranging from 0.470 to 0.535 ) and 0.814 (ranging from 0.800 to 0.828), respectively. Comparatively higher results observed by Parmar et al., (2007) where average heterozygosity values were to be $0.721,0.694$ and 0.689 in Jet black, Golden and Pencilled varieties of Kadaknath chicken, respectively and overall heterozygosity value for all the microsatellite loci among all the three varieties was observed to be 0.701 .

Vij et al., (2006) reported the observed heterozygosity values in Punjab Brown chicken ranging from 0.093 (MCW 305) to 0.863 (HUJ 3) with mean heterozygosity of 0.601 also revealed high heterozygosity level. Tantia et al., (2006) revealed the observed heterozygosity values for various loci in 15 chicken breeds ranging between 0.528 (MCW 266 ) to 0.875 (HUJ 3) with mean value of 0.702 showing a higher genetic variability compared to present study. Babar et al., (2012) estimated overall observed and expected heterozygosity $(\mathrm{He})$ value for microsatellite loci among four varieties of Pakistani Aseel chicken to be 0.3985 and 0.8329, respectively. Where observed heterozygosity is lower than but expected heterozygosity is comparatively higher than present study.

\section{Fixation index $\left(\mathrm{F}_{\mathrm{IS}}\right)$}

Wright's Fixation index also known as inbreeding coefficient is the proportion of the variance in the subpopulation contained in an individual, showing heterozygote deficit within population. The Fixation Index $\left(\mathrm{F}_{\mathrm{IS}}\right)$ value for all 25 microsatellite loci ranged from 0.075 (MCW 59) to 0.683 (MCW 73) with mean of 0.309 (Table 2) showing a considerable level of inbreeding present in native chicken population due to lack of systematic breeding. Similar results obtained in Esfahani et al., (2012) where observed mean $\mathrm{F}_{\mathrm{IS}}$ value to be 0.284 in native chicken breed in Iran. Pandey et al., (2005) observed mean $\mathrm{F}_{\text {IS }}$ to be 0.240 in Ankleshwar chicken. Vij et al., (2006) observed $F_{I S}$ value ranging from -0.010 (LEI 80) to 0.655 (LEI 147) with mean of 0.248 showing comparable level of inbreeding in Punjab Brown chicken. Kaya and Yildiz (2008) also observed mean $F_{\text {IS }}$ value to be 0.301 in Turkish native chicken showing similar level of inbreeding to the present study.

High level of inbreeding found in Babar et al., (2011) where observed mean $F_{I S}$ to be 0.450 in four Varieties viz. Lakha, Mushki, Mianwali and Peshawari of Pakistani Aseel chicken. Mukesh et al., (2011) also reported $\mathrm{F}_{\text {IS }}$ value ranged between 0.230 (MCW 81) to 0.755 (MCW 37) with mean $\mathrm{F}_{\text {IS }}$ to be 0.478 in Red Jungle fowl of Northern India. Soltan et al., (2017) also reported the mean $\mathrm{F}_{\text {IS }}$ value 0.369 and 0.451 in Norfa and Sinai native chicken of Egypt also showing higher inbreeding level to present estimate. Karsli and Balcioğlu (2019) estimated high $\mathrm{F}_{\text {IS }}(0.47)$ in six brown layer pure line chicken than present estimate. Lower inbreeding found in Abebe et al., (2015) where means FIS value to be 0.187 in five local Swedish chicken breeds. Ding et al., (2010) reported the mean $\mathrm{F}_{\mathrm{IS}}$ value to be $0.249,0.182$ and 0.159for Bian, Jinghai and Youxi Chinese native chicken, respectively also revealed low level of inbreeding than the present estimate.

\section{Polymorphic information content (PIC)}

Polymorphic Information Content (PIC) for all the 25 loci values ranged from 0.494 (ADL 158 ) to 0.883 (ADL 136) with mean 0.747 indicating abundant genetic diversity in native chicken and reflecting the possibility of using these loci as candidate genes for the future genetic studies of indigenous chicken breeds. 
Table.1 Details of microsatellite primers used in present study

\begin{tabular}{|c|c|c|c|c|c|}
\hline $\begin{array}{l}\text { Microsatelli } \\
\text { te Locus }\end{array}$ & & Sequence $\left(5,3{ }^{\prime}\right)$ & $\begin{array}{c}\text { Chromosomal } \\
\text { Location/ } \\
\text { Linkage } \\
\text { Group }\end{array}$ & $\begin{array}{c}5^{\prime} \\
\text { labellin } \\
\text { g with }\end{array}$ & $\begin{array}{c}\text { Multiplex PCR } \\
\text { Set with } \\
\text { Annealing } \\
\text { temperature }\end{array}$ \\
\hline \multirow[t]{2}{*}{ HUJ-2 } & $\mathrm{F}$ & CATCTCACAGAGCAGCAGTG & 17 & FAM & \multirow{8}{*}{$\begin{array}{c}\text { Set-I } \\
\left(57^{\circ} \mathrm{C}\right)\end{array}$} \\
\hline & $\mathrm{R}$ & GAATCCTGGATGTCAAAGCC & & & \\
\hline \multirow[t]{2}{*}{ ADL136 } & $\mathrm{F}$ & TGTCAAGCCCATCGTATCAC & \multirow[t]{2}{*}{9} & \multirow[t]{2}{*}{ HEX } & \\
\hline & $\mathrm{R}$ & ССАССТССТТСТССТGTTCA & & & \\
\hline \multirow[t]{2}{*}{ LEI-146 } & $\mathrm{F}$ & TCAAGCCACCAAAGTGCTTGG & \multirow[t]{2}{*}{1} & \multirow[t]{2}{*}{ TET } & \\
\hline & $\mathrm{R}$ & GATCACTCTGCTCATAGCAGT & & & \\
\hline \multirow[t]{2}{*}{ ADL-23 } & $\mathrm{F}$ & CTTCTATCCTGGGCTTCTGA & \multirow[t]{2}{*}{5} & \multirow[t]{2}{*}{ FAM } & \\
\hline & $\mathrm{R}$ & CCTGGCTGTGTATGTGTTGC & & & \\
\hline \multirow[t]{2}{*}{ ADL-158 } & $\mathrm{F}$ & TGGCATGGTTGAGGAATACA & \multirow[t]{2}{*}{10} & \multirow[t]{2}{*}{ HEX } & \multirow{8}{*}{$\begin{array}{l}\text { Set-II } \\
\left(57^{\circ} \mathrm{C}\right)\end{array}$} \\
\hline & $\mathrm{R}$ & TAGGTGCTGCACTGGAAATC & & & \\
\hline \multirow[t]{2}{*}{ HUJ-12 } & $\mathrm{F}$ & GTCTCATGCTATGAGAGTGG & \multirow[t]{2}{*}{8} & \multirow[t]{2}{*}{ TET } & \\
\hline & $\mathrm{R}$ & CCTCTGGTTGAATCAGTCTG & & & \\
\hline \multirow[t]{2}{*}{ ADL-267 } & $\mathrm{F}$ & AAACCTCGATCAGGAAGCAT & \multirow[t]{2}{*}{ C3E6 } & \multirow[t]{2}{*}{ FAM } & \\
\hline & $\mathrm{R}$ & GTTATTCAAAGCCCCACCAC & & & \\
\hline ADL-176 & $\mathrm{F}$ & TTGTGGATTCTGGTGGTAGC & 2 & FAM & \\
\hline & $\mathrm{R}$ & TTCTCCCGTAACACTCGTCA & & & \\
\hline MCW-1 & $\mathrm{F}$ & TGTCACAGTGGGGTCATGGACA & C4E28 & FAM & Set-III \\
\hline & $\mathrm{R}$ & ACACGTCCTGTGTTCACATGCCTGT & & & $\left(54^{\circ} \mathrm{C}\right)$ \\
\hline MCW-16 & $\mathrm{F}$ & ATGGCGCAGAAGGCAAAGCGATAT & 3 & FAM & \\
\hline & $\mathrm{R}$ & TGGCTTCTGAAGCAGTTGCTATGG & & & \\
\hline MCW-51 & $\mathrm{F}$ & GGAACAAGCTCTTTCTTCTTCCCG & C3E6 & TET & \\
\hline & $\mathrm{R}$ & TCATGGAGGTGCTGGTACAAAGAC & & & \\
\hline MCW-59 & $\mathrm{F}$ & AAGTGCCTTTGCTATCCTGATTGG & C1E2 & TET & \\
\hline & $\mathrm{R}$ & AACTCCTATTGTGCAGCAGCTTAT & & & \\
\hline MCW7 & $\mathrm{F}$ & AGCAAAGAAGTGTTCTCTGTTCAT & 1 & FAM & Set IV \\
\hline & $\mathrm{R}$ & АCCCTGCAAACTGGAAGGGTCTCA & & & $\left(59^{\circ} \mathrm{C}\right)$ \\
\hline MCW73 & $\mathrm{F}$ & TATTTCACCCACGGGGACGAATAC & C33E46 & HEX & \\
\hline & $\mathrm{R}$ & AGGGTGCTGAGAGCTGCCAATGTC & & & \\
\hline MCW49 & $\mathrm{F}$ & AGCGGCGTTGAGTGAGAGGAGCGA & 1 & HEX & \\
\hline & $\mathrm{R}$ & TCCCCAACCCGCGGAGAGCGCTAT & & & \\
\hline ADL-39 & $\mathrm{F}$ & GCTACAACGCTTCAAACCTG & 15 & TET & Set- V \\
\hline & $\mathrm{R}$ & ACAAACAAACCAAAAAACCT & & & $\left(57^{\circ} \mathrm{C}\right)$ \\
\hline ADL-44 & $\mathrm{F}$ & AAGTGGTTTATTGAAGTAGA & 12 & FAM & \\
\hline & $\mathrm{R}$ & CTGTGGTGTTGCGTTAGTTG & & & \\
\hline ADL210 & $\mathrm{F}$ & ACAGGAGGATAGTCACACAT & 11 & FAM & \\
\hline & $\mathrm{R}$ & GCCAAAAAGATGAATGAGTA & & & \\
\hline MCW-11 & $\mathrm{F}$ & TAAAATTTATCTTTGAAAATGCCT & 1 & HEX & Set-VI \\
\hline & $\mathrm{R}$ & GAGAAACATGTATTTCCAATTATTC & & & $\left(48^{\circ} \mathrm{C}\right)$ \\
\hline ADL-102 & $\mathrm{F}$ & TTCСАССТТТСТТТTТТАТT & 10 & FAM & \\
\hline & $\mathrm{R}$ & GCTCCАСТCССТTCТАACСC & & & \\
\hline ADL-172 & $\mathrm{F}$ & CCCTACAACAAAGAGCAGTG & E42 & HEX & \\
\hline & $\mathrm{R}$ & CTATGGAATAAAATGGAAAT & & & \\
\hline MCW-43 & $\mathrm{F}$ & TGACTACTTTGATACGCATGGAGA & 1 & FAM & Set-VII \\
\hline & $\mathrm{R}$ & CACCAAGTAGACGAAAACACATTT & & & $\left(57^{\circ} \mathrm{C}\right)$ \\
\hline LEI-65 & $\mathrm{F}$ & TGAAACATGTATGGAGTCTCAGCA & $\mathrm{C} 3$ & FAM & \\
\hline & $\mathrm{R}$ & GACAGCTAAATGCCAGTTCATGG & & & \\
\hline ADL-34 & $\mathrm{F}$ & AACCTAAAAACTCCTGCTGC & 20 & HEX & \\
\hline & $\mathrm{R}$ & GGGAACCTGTGGGCTGAAAG & & & \\
\hline HUJ-1 & $\mathrm{F}$ & CCATCCGCTTATACAGAGCACA & E01 & TET & \\
\hline & $\mathrm{R}$ & СССТTTGTTAACACCTACTGCA & & & \\
\hline
\end{tabular}


Table.2 Heterozygosity and polymorphism parameters for microsatellite markers in native chicken

\begin{tabular}{|c|c|c|c|c|c|c|c|c|}
\hline Locus & $\mathbf{N a}$ & $\mathrm{Ne}$ & I & Ho & He & uHe & $\mathbf{F}_{\text {IS }}$ & PIC \\
\hline HUJ 2 & 11 & 4.412 & 1.872 & 0.733 & 0.773 & 0.780 & 0.052 & 0.755 \\
\hline ADL 136 & 15 & 9.219 & 2.456 & 0.383 & 0.892 & 0.899 & 0.570 & 0.883 \\
\hline LEI 146 & 11 & 6.679 & 2.047 & 0.650 & 0.850 & 0.857 & 0.236 & 0.833 \\
\hline ADL 23 & 9 & 5.459 & 1.914 & 0.800 & 0.817 & 0.824 & 0.021 & 0.795 \\
\hline ADL 158 & 9 & 2.074 & 1.182 & 0.433 & 0.518 & 0.522 & 0.163 & 0.494 \\
\hline HUJ 12 & 14 & 8.834 & 2.352 & 0.650 & 0.887 & 0.894 & 0.267 & 0.876 \\
\hline ADL 267 & 9 & 3.647 & 1.615 & 0.417 & 0.726 & 0.732 & 0.426 & 0.694 \\
\hline ADL 176 & 8 & 4.621 & 1.764 & 0.400 & 0.784 & 0.790 & 0.490 & 0.758 \\
\hline MCW 1 & 9 & 3.209 & 1.467 & 0.550 & 0.688 & 0.694 & 0.201 & 0.637 \\
\hline MCW 16 & 9 & 4.955 & 1.842 & 0.683 & 0.798 & 0.805 & 0.144 & 0.775 \\
\hline MCW 51 & 7 & 5.221 & 1.752 & 0.400 & 0.808 & 0.815 & 0.505 & 0.781 \\
\hline MCW 59 & 10 & 5.835 & 1.966 & 0.767 & 0.829 & 0.836 & 0.075 & 0.809 \\
\hline MCW 7 & 8 & 3.646 & 1.591 & 0.533 & 0.726 & 0.732 & 0.265 & 0.694 \\
\hline MCW 73 & 10 & 6.283 & 2.027 & 0.267 & 0.841 & 0.848 & 0.683 & 0.823 \\
\hline MCW 49 & 10 & 3.517 & 1.571 & 0.700 & 0.716 & 0.722 & 0.022 & 0.722 \\
\hline ADL 39 & 10 & 2.972 & 1.528 & 0.467 & 0.663 & 0.669 & 0.297 & 0.637 \\
\hline ADL 44 & 8 & 5.325 & 1.762 & 0.600 & 0.812 & 0.819 & 0.261 & 0.785 \\
\hline ADL 210 & 8 & 3.221 & 1.512 & 0.250 & 0.690 & 0.695 & 0.637 & 0.657 \\
\hline MCW 11 & 10 & 4.855 & 1.872 & 0.433 & 0.794 & 0.801 & 0.454 & 0.771 \\
\hline ADL 102 & 10 & 3.738 & 1.792 & 0.383 & 0.733 & 0.739 & 0.477 & 0.716 \\
\hline ADL 172 & 6 & 4.306 & 1.568 & 0.067 & 0.768 & 0.774 & 0.913 & 0.73 \\
\hline MCW 43 & 6 & 3.533 & 1.416 & 0.633 & 0.717 & 0.723 & 0.117 & 0.669 \\
\hline LEI 65 & 10 & 3.683 & 1.721 & 0.650 & 0.728 & 0.735 & 0.108 & 0.706 \\
\hline ADL 34 & 11 & 6.883 & 2.096 & 0.683 & 0.855 & 0.862 & 0.201 & 0.839 \\
\hline HUJ 1 & 12 & 7.171 & 2.185 & 0.733 & 0.861 & 0.868 & 0.148 & 0.848 \\
\hline Mean & 9.60 & 4.932 & 1.795 & 0.531 & 0.771 & 0.777 & 0.309 & 0.74748 \\
\hline SE & 0.420 & 0.360 & 0.060 & 0.037 & 0.017 & 0.017 & 0.046 & 0.01774 \\
\hline
\end{tabular}

(Na: No. of alleles, Ne: No. of effective alleles, I: Shannon's Information Index, Ho: Observed heterozygosity, He: Expected heterozygosity and $\mu \mathrm{He}$ : Unbiased expected heterozygosity,

PIC: Polymorphism Information Content and $\mathrm{F}_{\mathrm{IS}}$ : Fixation Index)

Comparable results found in Pandey et al., (2003) where PIC value varying from 0.49 (MCW 49) to 0.83 (ADL 136) with average of 0.64 in Aseel breed. From 0.35 (MCW 59) to 0.82 (ADL 136) with an average of 0.66 in Miri breed and 0.39 (MCW 14) to 0.82 (ADL 176) with mean of 0.63 in Nicobari breed. Pandey et al., (2005) also observed PIC values ranging from $0.283(\mathrm{MCW} 4)$ to 0.831 (ADL 171) with mean value of 0.623 in
Ankleshwar chicken. Vij et al., (2006) reported PIC value ranging from 0.439 (HUJ 2) to 0.878 (LEI 120) with mean value of 0.672 in Punjab Brown chicken.

Parmar et al., (2007) also observed PIC values to be $0.671,0.699$, and 0.617 in Jet black, Golden and Pencilled varieties of Kadaknath breed, respectively. Overall PIC values among all the three varieties were 
found to be 0.662. Babar et al., (2012) reported mean polymorphic information content (PIC) values to be $0.67,0.69,0.71$ and 0.65 in individual varieties of Pakistani Aseel chicken, similar to the present study.

Higher estimate found in Tantia et al., (2006) where PIC values for the 25 loci studied were very high and ranged from 0.618 (LEI 90) to 0.904 (MCW 228) with mean of 0.818 in 15 defined chicken breeds of India. Also, Soltan et al., (2017) observed the mean PIC value in the two chicken strains were greater than 0.5 (0.807 and 0.776 for Norfa and Sinai chickens, respectively).

Mukesh et al., (2011) revealed 14 microsatellite having PIC value more than 0.5 among 15 microsatellite markers in Red Jungle fowl in Northern India. Similarly, in present study only one microsatellite i.e. 0.494 (ADL 158) had PIC $<0.5$.

\section{Within population genetic variability}

The Shannon index is a parameter for determining diversity. The value for Shannon index (I) is ranged from 1.416 (MCW 43) to 2.456 (ADL 136) with mean of 1.795 which indicated high gene diversity within native chicken population (Table 2).

Similar results found in Pandey et al., (2005) where the Shannon index ranged from 0.773 (MCW 41) to 2.093 (ADL 171) with mean of 1.400 in Ankleshwar chicken. Mukesh et al., (2011) also observed Shannon index value ranging from 0.947 (MCW 98) to 2.296 (ADL 268) and mean value to be 1.685 in Red Jungle fowl in Northern India. Babar et al., (2012) reported mean value of Shannon index to be $1.442,1.538,1.594$ and 1.371 in Lakha (China), Mushki, Mianwali, Peshwari respectively in varieties of Pakistani Aseel, similar to present estimate. The genetic diversity analysis of native chicken population revealed abundant genetic diversity and provided basic information for future detailed studies to preserve animal genetic resource of Gujarat. All the microsatellite loci typed were polymorphic with reasonable to high informativeness which can effectively be used for genetic characterization of indigenous chicken population.

\section{References}

Abebe, A. S., Mikko, S., and Johansson, A. M. (2015). Genetic diversity of five local Swedish chicken breeds detected by microsatellite markers. PLoS One, 10 (4), e0120580.

Babar, M. E., Nadeem, A., Hussain, T., Wajid, A., Shah, S. A., Iqbal, A., and Akram, M. (2012). Microsatellite marker based genetic diversity among four varieties of Pakistani Aseel Chicken. Pakistan Veterinary Journal, 32 (2), 237-241.

Ding, Fu-Xiang, Gen-Xi Zhang, Jin-Yu Wang, Yuan Li, Li-Jun Zhang, Yue Wei, Hui-Hua Wang, Li Zhang, and QiRuiHou. (2010). Genetic diversity of a Chinese native chicken breed, Bian chicken, based on twenty-nine microsatellite markers. AsianAustralasian Journal of Animal Sciences, 23 (2), 154-161.

Esfahani, E. N., Eskandarinasab, M. P., Khanian, S. E., Nikmard, M., and Molaee, V. (2012). Genetic diversity of a native chicken breed in Iran. Journal of Genetics, 1-4.

John, S. W. M., Weitzner, G., Rozen, R., and Scriver, C. R. (1991). A rapid procedure for extracting genomic DNA from leukocytes. Nucleic Acids Research, 19 (2), 408.

Karsli, T., and Balcıoğlu, M. S. (2019). Genetic characterization and population structure of six brown layer pure lines 
using microsatellite markers. AsianAustralasian Journal of Animal Sciences, 32 (1), 49.

Kaya, M., and Yıldiz, M. A. (2008). Genetic diversity among Turkish native chickens, Denizli and Gerze, estimated by microsatellite markers. Biochemical Genetics, 46 (7-8), 480-491.

Kolstad, N. and Abdou, F.H. (2000). NORFA: The Norwegian-Egyptian project for improving local breeds of laying hens in Egypt. Workshop on Developing Breeding Strategies for Lower Input Production Environment, Bella, Italy, In: Proceedings of the ICAR Technical Series, 3, 301-306.

Mukesh, R., Kalsi, S., Mandhan, R. P., \&Sathyakumar, S. (2011). Genetic diversity studies of red Jungle fowl across its distribution range in Northern India. Asian Journal Biotechnology, 3, 293-301.

Pandey, A. K., Kumar, D., Sharma, R., Sharma, U., Vijh, R. K., and Ahlawat, S. P. S. (2005). Population structure and genetic bottleneck analysis of Ankleshwar poultry breed by microsatellite markers. AsianAustralasian Journal of Animal Sciences, 18 (7), 915-921.

Pandey, A. K., Mishra, B., Chaudhary, P., Tantia, M. S., and Vijh, R. K. (2003). Microsatellite analysis of three poultry breeds of India. Asian-Australasian Journal of Animal Sciences, 15 (11), 1536-1542.

Parmar, S. N. S., Tolenkhomba, T. C.,
Thakur, M. S., Joshi, C. G., Rank, D. N., Solanki, J. V., and Pillai, P. V. A. (2007). Analysis of genetic relationship among three varieties of indigenous Kadaknath breed using 25 chicken microsatellite markers. Indian Journal of Biotechnology, 6 (1), 205-209.

Rajkumar, U., Gupta, B. R., and Reddy, A. R. (2008). Genomic heterogeneity of chicken populations in India. AsianAustralasian Journal of Animal Sciences, 21 (12), 1710-1720.

Soltan, M. E.; Enab, A. A.; Eman M. Abou-Elewa and Farrag, S. A. (2016). Genetic characterization of a local Egyptian chicken strain Norfa using microsatellite markers. Procc. of $9^{\text {th }}$ International Poultry Conference, 7-10 November, Hurghada, Red Sea Egypt. pp: 188-202.

Soltan, M., Farrag, S., Enab, A., Abou-Elewa, E., El-Safty, S., and Abushady, A. (2017). Sinai and Norfa chicken diversity revealed by microsatellite markers. South African Journal of Animal Science, 48 (2), 307-315.

Tantia, M. S., Vijh, R. K., Kumar, S. B., Mishra, B., and Ahlawat, S. P. S. (2006). Genetic diversity analysis of chicken breeds of India. The Indian Journal of Animal Sciences, 76(12), 1033-1038.

Vij, P. K., Tantia, M. S., and Vijh, R. K. (2006). Characterization of Punjab brown chicken. Animal Genetic Resources, 39, 65-76.

\section{How to cite this article:}

Chaudhary, D. F., R. S. Joshi, D. N. Rank and Chaudhary, J. D. 2020. Microsatellite based Genetic Characterization Study in Native Chicken Population of North Gujarat. Int.J.Curr.Microbiol.App.Sci. 9(04): 1562-1569. doi: https://doi.org/10.20546/ijcmas.2020.904.183 